\title{
Fuel Subsidies, Fuel Consumption, and Road Transport Emissions: A systematic review
}

\author{
Ahmad Razi Ramli', Juliana Mohd Abdul Kadir², Norashikin Ismail3, \\ Akmal Aini Othman ${ }^{4}$, Patricia C. Melo ${ }^{5}$ \\ 11,2,3,4 Faculty of Business Management, Universiti Teknologi MARA Johor, Malaysia \\ 5 ISEG Lisbon School of Economics \& Management, Universidade de Lisboa, Portugal
}

1ahmadrazi@uitm.edu.my, 2julia593@uitm.edu.my, 3noras479@uitm.edu.my, 4akmal123@uitm.edu.my, 5pmelo@iseg.ulisboa.pt Tel: +601110878845

\begin{abstract}
The growing clamor about the climate crisis has brought into focus the need for action to drastically reduce $\mathrm{CO}_{2}$ emissions, particularly from the road transport sector. This systematic literature review examines the nexus between fossil fuel subsidies, fuel consumption, and $\mathrm{CO}_{2}$ emissions from the road transport sector. Despite numerous research contributions that provide the foundation on this topic, the body of research appears to be quite fragmented with regard to the stated nexus. This systematic literature review consolidates currently available research and provides the basis for further research on the connection between fuel subsidy, fuel consumption, and $\mathrm{CO}_{2}$ emissions.
\end{abstract}

Keywords: Fossil Fuel Subsidy; Transport Emissions; Subsidy Reform; Systematic Literature Review

eISSN: 2398-4287@ 2021. The Authors. Published for AMER ABRA cE-Bs by e-International Publishing House, Ltd., UK. This is an open access article under the CC BYNC-ND license (http://creativecommons.org/licenses/by-nc-nd/4.0/). Peer-review under responsibility of AMER (Association of Malaysian Environment-Behaviour Researchers), ABRA (Association of Behavioural Researchers on Asians/Africans/Arabians) and CE-Bs (Centre for Environment-Behaviour Studies), Faculty of Architecture, Planning \& Surveying, Universiti Teknologi MARA, Malaysia.

DOI: https://doi.org/10.21834/ebpj.v6i16.2721

\subsection{Introduction}

The Paris Agreement has brought into focus of the need to ensure that the transportation sector is not neglected in the effort to mitigate global greenhouse gas (GHG) emissions. The Intergovernmental Panel on Climate Change (IPCC, 2014) has indicated that while there are many pathways to mitigate global warming, all require a substantial reduction in $\mathrm{CO}_{2}$ emissions. The transport sector as a whole is a significant contributor to global warming, accounting for approximately $8 \mathrm{GtCO}_{2}$ or $24 \%$ of global $\mathrm{CO}_{2}$ emissions (IEA, 2020). Out of the total emissions, three-quarters of the reported transport emissions originated from the road transport sector. What is worrying is that in the period 2000-2017, transport emissions have consistently grown across every region despite the various global economic crises. In Malaysia, the same scenario is replayed. The transport sector is the second-largest emitter of GHG, accounting for $20 \%$ of Malaysia's GHG emissions. Within this $20 \%$, road transport is again the biggest culprit accountable for a disproportionate amount of $18 \%$ of the GHG emissions (MESTECC, 2018).

This research analyses through a survey of literature the current situation with regards to road transport fossil fuel subsidies across the world. The main aim is to highlight the nexus between fossil fuel subsidies, fuel consumption, and $\mathrm{CO}_{2}$ emissions from the road transport sector. Therefore, the objective of the present study is twofold. First to determine the relationship between fuel subsidies and fuel consumption. Second to examine the association between fuel subsidies and $\mathrm{CO}_{2}$ emissions. In the survey of the literature, fuel

eISSN: 2398-4287@ 2021. The Authors. Published for AMER ABRA cE-Bs by e-International Publishing House, Ltd., UK. This is an open access article under the CC BYNC-ND license (http://creativecommons.org/licenses/by-nc-nd/4.0/). Peer-review under responsibility of AMER (Association of Malaysian Environment-Behaviour Researchers), ABRA (Association of Behavioural Researchers on Asians/Africans/Arabians) and cE-Bs (Centre for Environment-Behaviour Studies), Faculty of Architecture, Planning \& Surveying, Universiti Teknologi MARA, Malaysia.

DOI: https://doi.org/10.21834/ebpj.v6i16.2721 
subsidy and its impacts will be highlighted. The provision of fossil fuel subsidies imposes enormous environmental costs: fossil fuel subsidies in the transport sector distort behavior by inducing overconsumption, dis-incentivize the transition towards cleaner vehicles and create a lock-in effect of carbon-intensive technologies, thus hindering climate change and GHG mitigation measures. The connection between fossil fuel subsidy reforms to the road sector transport emissions has been exhaustively argued in many studies; such as those by Rentschler and Brazilian (2016) and Stefanski (2016). A recurring theme in these studies is that elimination of fossil fuel subsidies may lead to a reduction in emissions relative to the reference scenario by 6.4 - 18\% (Merrill, et al., 2015; Schwanitz, et al., 2014; Magné, et al., 2014).

This paper provides a systematic literature review (SLR) on the role of fossil fuel subsidies in the road transport sector on fuel consumption and its subsequent environmental impact. While there is numerous research on fuel subsidy, the body of research that specifically focuses on the nexus of fuel subsidy, fuel consumption, and environmental effects appears to be limited and fragmented. While there is much research on the impact of fuel subsidy in terms of distributional effects and fiscal impacts, there is an evidence gap in terms of how fuel subsidy, in the context of road transport, exacerbates consumption and environmental consequences. Therefore, this paper is aimed at capturing, summarizing, synthesizing, and evaluating literature published on the stated nexus.

To address the evidence base gap, this paper investigates the range of different fuel subsidies in terms of approach, distribution countries, and outcome. The review gives attention to specific mentions of the effect on fuel consumption and the environmental consequences. The findings of this paper may provide the basis for further research into the matter and inform stakeholders on the need for evidence-based policy to enact effective fuel subsidy reform to mitigate unintended environmental consequences from the road transport sector.

This paper is structured as follows. The SLR methodology, framework, and sample identification are presented in the following section. Section 3 presents the findings from the selected studies, distinguishing the effect of fuel subsidies on fuel consumption and $\mathrm{CO}_{2}$ emissions. The discussion section synthesizes the findings and considers the implications in the context of consequences from pursuing fuel subsidy policies. Finally, the paper finishes with a brief conclusion and future research directions.

\subsection{Methodology and Sample Identification}

To facilitate the objective attainment of this review, two research questions were constructed: (1) what is the relationship between fuel subsidy and fuel consumption? (2) what is the role of fuel subsidy and how does it affect the environment?

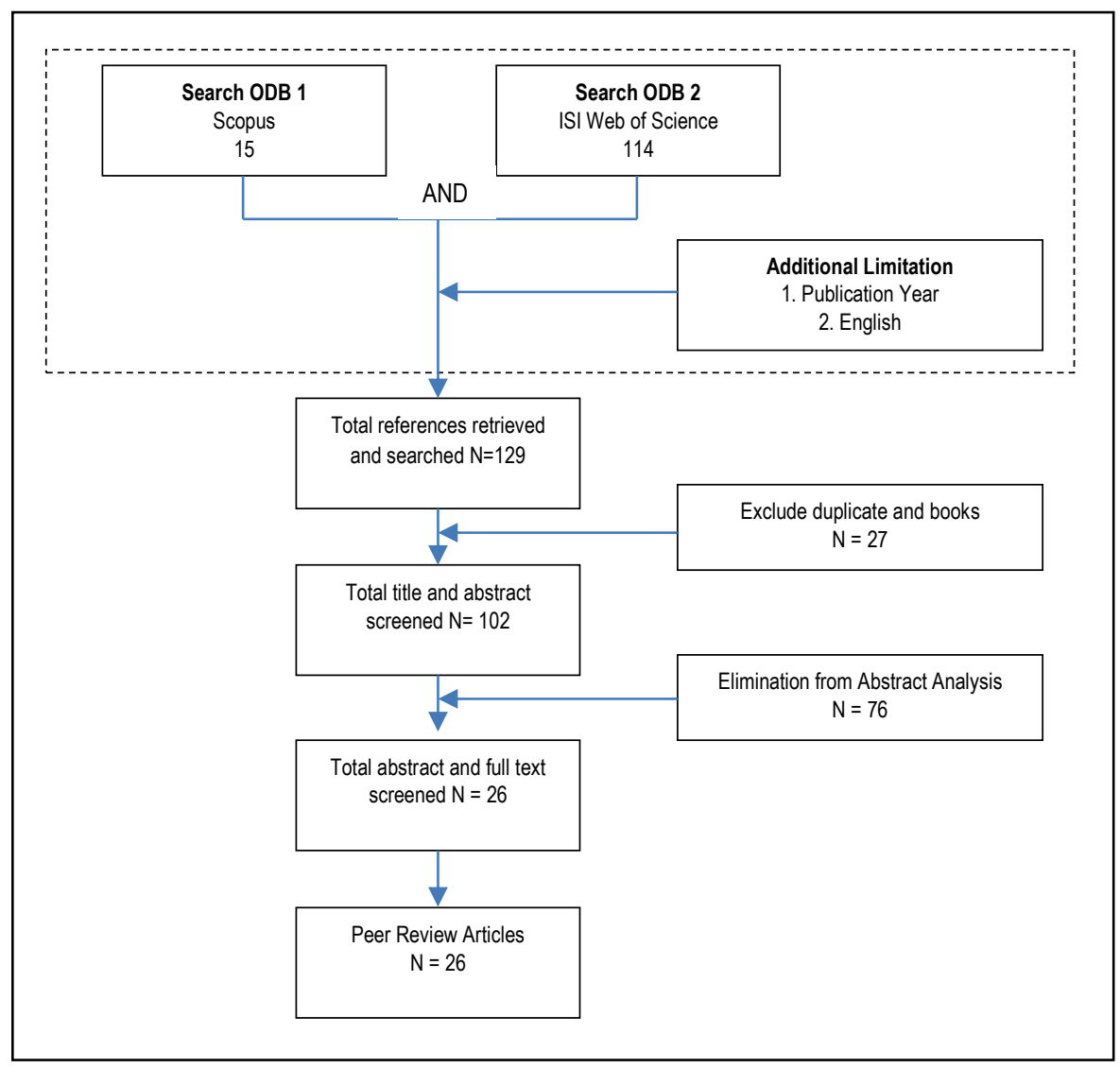

Figure 1: Selection of Article Flow Diagram

Note: ODB is the abbreviation for an online database.

The research design of the study is to identify relevant literature, using Systematic Literature Review (SLR) and employing a search 
strategy via two online databases (Scopus and ISI Web of Science) for studies published within the period 2001-2020. The search code applied the following keywords: "fuel-subsid ${ }^{*}$ or petrol-subsid* or diesel-subsid* or energy-subsid" and fuel and assis* and fuel-consum* and distributional". In this study, only full-text peer-reviewed articles are considered, the studies must be either in article form or conference paper, and the articles must be in English.

The selection of rather broad terms was used to reflect the objective of the research between fuel subsidies and fuel consumption and with the scope of the study, the review was extended to see the effects primarily on emissions but to a lesser extent also generally to the environment. The paper accepts all types of fuel subsidies such as fuel subsidy, fossil subsidy, petrol subsidy, diesel subsidy, and energy subsidies and excluded studies from book and book chapters. Furthermore, the paper that did not contain fuel consumption, fuel assistance, or distributional impact were excluded. As stated, the second criterion applied was that the papers included must relate to the issues of fuel subsidy and the environment.

The search was executed on November 2nd, 2020, and yielded a total of 129 papers. A filtering process (Figure 1) was conducted by removing all duplicate articles from the lists, resulting in 127 papers remaining to be considered. Of these, 25 sources from books and working papers were further excluded from the lists leaving only 102 papers for the abstract analysis.

In the abstract analysis stage, the abstracts of these articles were screened for eligibility. As pointed out in the introduction, this literature review focuses on studies that have fuel consumption and environmental effects. Therefore, a pre-selection of papers that do not fulfill this requirement could be made and consequently eliminated. Papers that were eliminated for example focused on renewable energy, energy consumption, energy poverty, taxation reform, competitiveness and trade, sustainable cities, and road traffic. Papers that try to examine the impact of fuel subsidies on output, gross domestic product, and other macroeconomic variables were also excluded from the analysis as these studies are not consistent with the focus of this research. After the abstract analysis, 76 papers were eliminated, with the sample for this review now consists of only 26 publications considered relevant for further analysis.

\subsection{Findings}

In total, the SLR identified 26 peer-reviewed articles that match the scope of the analysis. Table 1 provides the list of articles included in the SLR together with their corresponding authors. The table also contains further information about the included studies with additional information about countries and the type of subsidies investigated. Additionally, columns containing the context of the studies (i.e. fuel consumption and environment) have also been included.

Although the number of studies included is relatively limited, it can be seen that the geographical coverage included in the studies is quite extensive. This has allowed this research to gauge the extent and breadth to which fuel subsidy has been linked to fuel consumption and environmental consequences. There are also multifaceted approaches in terms of the type of methodology used, ranging from literature and discussion-based approaches to the estimation of parameters using econometrics models. Additionally, from a more general observation, it is apparent that fuel subsidies are mostly an issue in developing countries rather than developed ones. This conforms to the expected norm, in which, in developed countries with mature market economies, fuel price is determined by the market.

\begin{tabular}{|c|c|c|c|c|c|c|}
\hline No & Year & Author(s) & Country & $\begin{array}{l}\text { Type of } \\
\text { Subsidy }\end{array}$ & $\begin{array}{c}\text { Fuel } \\
\text { Consumption }\end{array}$ & Environment \\
\hline 1 & 2020 & Solarin, S.A. & $\begin{array}{l}35 \text { emerging and } \\
\text { developing countries }\end{array}$ & Fossil fuel & $\sqrt{ }$ & $\sqrt{ }$ \\
\hline 2 & 2020 & $\begin{array}{l}\text { Chepeliev, M., van der Mensbrugghe, } \\
\text { D. }\end{array}$ & 25 countries & Fossil fuel & $\sqrt{ }$ & $\sqrt{ }$ \\
\hline 3 & 2019 & Adetutu, M.O., Weyman-Jones, T.G & 68 developing countries & Fuel/ Gasoline & $\sqrt{ }$ & $\sqrt{ }$ \\
\hline 4 & 2019 & Monasterolo, I., Raberto, M. & Variety countries & Fossil fuel & $\sqrt{ }$ & $\sqrt{ }$ \\
\hline 5 & 2018 & Henseler, M., Maisonnave, $\mathrm{H}$. & South Africa & Fossil Fuel & $\sqrt{ }$ & \\
\hline 6 & 2018 & $\begin{array}{l}\text { Ghorbani, A., Rahimpour, M.R., Ghasemi, } \\
\text { Y., Raeissi, S. }\end{array}$ & Iran & Diesel & $\sqrt{ }$ & $\sqrt{ }$ \\
\hline 7 & 2018 & Ghoddusi, H., Rafizadeh, N., Rahmati, M.H. & Iran & Gasoline & $\sqrt{ }$ & \\
\hline 8 & 2018 & Li, J., Sun, C. & China & Fossil fuel & & $\sqrt{ }$ \\
\hline 9 & 2018 & Li, Y., Shi, X., Su, B. & Malaysia & Fuel & $\sqrt{ }$ & $\sqrt{ }$ \\
\hline 10 & 2017 & Troncoso, K., da Silva, A.S. & Latin America & Petrol/ LPG & $\sqrt{ }$ & $\sqrt{ }$ \\
\hline 11 & 2017 & Mundaca, G. & $\begin{array}{l}\text { The Middle East and } \\
\text { North African region }\end{array}$ & Fossil fuel & $\sqrt{ }$ & $\sqrt{ }$ \\
\hline 12 & 2017 & Coady, D., Parry, I., Sears, L., Shang, B.P. & Variety countries & Fossil fuel & $\sqrt{ }$ & $\sqrt{ }$ \\
\hline 13 & 2017 & Wesseh, P.K., Lin, B.Q. & Ghana & Fossil fuel & $\sqrt{ }$ & $\sqrt{ }$ \\
\hline
\end{tabular}




\begin{tabular}{|c|c|c|c|c|c|c|}
\hline 14 & 2017 & Matsuo, T., Schmidt, T.S. & $\begin{array}{l}\text { Lebanon, Saudi Arabia, } \\
\text { South Africa and, Tunisia }\end{array}$ & Fossil fuel & & $\sqrt{ }$ \\
\hline 15 & 2017 & Rentschler, J., Bazilian, M. & Variety countries & Fossil fuel & $\sqrt{ }$ & $\sqrt{ }$ \\
\hline 16 & 2017 & Davis, L.W. & MENA & Fossil fuel & $\sqrt{ }$ & $\sqrt{ }$ \\
\hline 17 & 2016 & $\begin{array}{l}\text { Choi, J.K., Bakshi, B.R., Hubacek, K., } \\
\text { Nader, J. }\end{array}$ & United States & Energy & & $\sqrt{ }$ \\
\hline 18 & 2015 & Rashchupkina, Y. & European Union & Fossil fuel & & $\sqrt{ }$ \\
\hline 19 & 2015 & Soile, I., Mu, X. & Nigeria & Fuel/ petrol & $\sqrt{ }$ & \\
\hline 20 & 2015 & Arzaghi, M., Squalli, J. & 32 countries & Fuel & $\sqrt{ }$ & \\
\hline 21 & 2014 & Burke, P.J. & Asia Pacific & Fossil fuel & & $\sqrt{ }$ \\
\hline 22 & 2014 & Ouyang, X., Lin, B. & China & Fuel/ energy & $\sqrt{ }$ & \\
\hline 23 & 2013 & Dartanto, $\mathrm{T}$. & Indonesia & Fuel & $\sqrt{ }$ & \\
\hline 24 & 2012 & $\begin{array}{l}\text { Del Granado, F.J.A., Coady, D., Gillingham, } \\
\text { R. }\end{array}$ & Developing countries & Fuel & $\sqrt{ }$ & \\
\hline 25 & 2012 & Lin, B., Li, A. & China & Fuel/ energy & $\sqrt{ }$ & \\
\hline 26 & 2001 & Koplow, D., Dernbach, J. & United States & Fossil fuel & & $\sqrt{ }$ \\
\hline
\end{tabular}

Source: Authors' Compilation

\subsection{Fuel Subsidies and Fuel Consumption}

Curbing carbon dioxide $\left(\mathrm{CO}_{2}\right)$ emissions is a necessary action to avoid extreme global warming scenarios. In the transport sector, this will require a significant reduction in fuel consumption since the energy requirement of the sector is still dominated by carbon-based fuel sources. It is believed that overconsumption of fossil fuel arises because of low consumer fuel prices, in many cases, due to fuel subsidies (Adetutu and Jones, 2019; Davis 2017; Coady, et al., 2017). This phenomenon is seen and experienced by a number of rich developing countries such as Algeria, Iran, Russia, Indonesia, and Malaysia (Vagliasindi, 2013). In addition, the Middle East and North African regions subsidize fossil fuels substantially and pushed the demand for fossil fuels (Mundaca, 2017).

The various studies supplied context on why fuel subsidies are provided with varying details on their broader economic implications to the respective countries. Within this broad scope, it is not difficult to see that Malaysia also falls within the group of nations that continues to provide fuel subsidy for the road transport sector. Generally, the higher fuel subsidies allude to the magnanimity of the policymakers as the subsidies are perceived to generate some form of benefit to society, particularly the poor. With subsidies, the general public can buy fuel at lower consumer prices for various socio-economic activities. In general, fuel subsidies are never intended to stimulate travel but since transport is a means to an end, it is to be expected as socio-economic activities increase, fuel consumption as a corollary will increase as well.

The unintended consequence of higher fuel consumption due to subsidies appears to be supported in the study by Mundaca (2017). In that particular study, fuel consumption is measured through the estimation of fuel demand elasticity with respect to price and income. It was found that the demand response for regions with a high subsidy is relatively higher compared to those without. The study also contrasted the demand response between different fuel types and found significantly higher elasticities for fuel with higher (diesel) as compared to fuel that receive less subsidy (petrol).

\subsection{Fuel Subsidies and Environmental Effects}

Even though fuel subsidies improve the welfare of society and stimulate economic growth, the contemporary view paints a rather murky picture in terms of its environmental effects. Adentutu and Jones (2019) for instance, found a positive correlation between petroleum, emissions, and fuel subsidies. In other words, there is evidence that fuel subsidies stimulate carbon dioxide $\left(\mathrm{CO}_{2}\right)$ emissions. While this is to be expected, it goes against the demand for a substantial reduction of GHG emissions that leads to global climate change. Thus, the imbalance between what is gained through fuel subsidies and the price it costs particularly to the environment and the society will have to be considered.

While different policy and cultural contexts may result in differing fuel consumption responses between countries reported within the SLR sample, it can be observed that there is a clear realization concerning the linkage between fuel consumption and its environmental consequences. With transport generally being one of the largest sectors consuming fossil fuel in developing countries, often case the environmental effect reported is in terms of the share of emissions due to the sector.

Considering the link between fuel subsidies and emissions, it is therefore not surprising that the elimination of subsidies is suggested as a mechanism to effectively achieve emissions reduction (Chepeliev and van der Mensbrugghe, 2020). Solarin (2020) indicated that since subsidies are mostly aimed at reducing prices of fuels, phasing out fuel subsidies is one way of initiating price reform with the impact being beneficial on the climate and society.

Further analysis also found that environmental effects in such studies may also cover matters such as wasteful consumption, barriers to investment, and issues related to health risk as well as road deaths (Rentschler and Brazilian, 2017; Burke, 2014). In the study by Solarin (2020), fuel subsidy is examined in the context of environmental degradation. While this is to be expected, it does indicate that 
there is a fragmented focus on the environmental effect of fuel subsidies, especially when the environmental effect appears to include more than just concerns about emissions.

\subsection{Discussion}

So how can this SLR be useful in informing future policy formulations and research? In the case of the fuel subsidy, fuel consumption, and environmental effect nexus it is first important to disentangle the direct and corollary relationship. On one end, the direct effect is relatively clear. One of the most important contributors to fuel consumption is the fuel price. In this relationship, it is to be expected that the lower fuel price setting due to the prevailing fuel price subsidy will have a positive effect on fuel consumption.

While increased fuel consumption is never the aim, often case the defining measure of success for the provision of fuel subsidy are other positive economic and social measures. Notably, when such yardsticks are used, the negative outcome from the higher amount of fuel consumption will be hidden and may not be of primary concern to policymakers. If curtailing fuel subsidies is perceived to have a disproportionately detrimental effect on other aspects of the economy and society, then fuel subsidy reform will have to include measures to tackle other areas apart from transportation. This may also be the reason why there is a gap in terms of studies that look exclusively into such linkage. Admittedly, studies that include broader aspects such as economic, fiscal, and distributional impacts with respect to fuel subsidies are relatively widely available.

For that matter, despite the growing clamor for actions to combat climate change, it is evident that linking the environmental consequences of elevated fuel consumption given the context above will likely have less impact on fuel subsidy reform. There is also further complexity if factors such as substitutability and fuel efficiency are taken into account. For example, fossil fuel subsidy removal may result in inter-fuel substitution which may have negative consequences in terms of emissions. Consider the case of substitutability between petrol and diesel. If the subsidy rate for petrol is reduced below the subsidy rate of diesel, this might inadvertently stimulate substitution from petrol to diesel. Considering that diesel fuel has higher carbon content as compared to petrol, such measures may not result in the desired $\mathrm{CO}_{2}$ emissions mitigation.

Additionally, further complexity is also introduced with the current transition of the fossil fuel-based vehicle fleet to electric vehicle technology. Substitutability here may simply mask a broader problem of transferring the tailpipe emissions from direct fossil fuel consumption to the equally polluting power plant-based energy sources due to vehicle charging.

The findings also reveal that governments play a significant role in the misalignment between fuel consumption and the subsequent environmental externalities (Monasterolo and Raberto, 2019). However, in many countries, fuel subsidy reforms are often difficult to implement due to the fear of political repercussions from such decisions (del Granado, et al., 2012).

\subsection{Conclusion and Recommendation}

This systematic literature review has focused on studies that explain the nexus linking fuel subsidies, fuel consumption, and emissions from the road transport sector. This comes at a time when there is an increased awareness of the need to drastically reduce $\mathrm{CO}_{2}$ emissions, especially from the road transport sector as part of the effort to meet emissions reduction targets worldwide.

While there is rising attention given, it was also found that a gap exists in the body of research particularly in the context of linking fossil fuel subsidy with $\mathrm{CO}_{2}$ emissions from the road transport sector. There is limited research investigating the stated nexus with the available research utilizing significantly different approaches in terms of measurement approaches and evaluation of outcome. This results in difficulties in making comparisons and identifying the forms of intervention that are suitable for policymaking.

At a minimum, this paper has highlighted how fuel subsidy is inextricably linked to $\mathrm{CO}_{2}$ emissions. Furthermore, it also found that any road transport fuel subsidy reform would also require solutions to address many other economic and social factors. Road transport fuel subsidy reform requires the incorporation of a variety of outcomes that are beyond the scope of energy consumption and emissions. Since transportation involves multiple stakeholders and various economic and societal aspects, perspectives which are centered only on energy consumption and emissions may not be adequate to enact policy changes.

This systematic literature review does have several important limitations. Firstly, only English papers were selected, and this has removed the possibility of investigating outcomes from many other sources not published in English. Additionally, the requirement of only including peer-reviewed articles has also removed important sources such as government policy documents and think tank reports related to the topic. While broad and international in perspective, the time frame chosen may have also affected the sample countries included with most of the articles dominated by issues related to developing countries.

This paper has identified the following areas for future research investigations. Firstly, there is a need to understand the effect of fuel substitutability on any road transport fossil fuel measures. Additionally, the effect of the current transition from fossil fuel to electric energy in powering vehicles should also be investigated especially in the context of emissions generated at the power plant

\section{Acknowledgments}

This study was funded by the Malaysian Ministry of Higher Education under the Fundamental Research Grant Scheme - 600-IRMI/FRGS $5 / 3$ (223/2019). The views expressed in this paper do not necessarily reflect the views of the Ministry. 


\section{Paper Contribution to Related Field of Study}

This paper contributes to the body of knowledge in the areas of energy and transport policy, energy economics, and carbon emissions.

\section{References}

Adetutu, M.O., \& Weyman-Jones, T.G. (2019). Fuel subsidies versus market power: is there a countervailing second-best optimum? Environmental and Resource Economics, 74(4), 1619-1646.

Arzaghi, M. \& Squalli, J. (2015). How price inelastic is demand for gasoline in fuel-subsidizing economies? Energy Economics, 117-124.

Burke, P.J. (2014). Green pricing in the Asia Pacific: an idea whose time has come? Asia \& the Pacific Policy Studies, 1(3), 561-575

Choi, J.K., Bakshi, B.R., Hubacek, K., \& Nader, J. (2016). A sequential input-output framework to analyze the economic and environmental implications of energy policies: Gas taxes and fuel subsidies. Applied Energy, 184, 830-839.

Coady, D., Parry, l., Sears, L., \& Shang, B. (2017). How large are global fossil fuel subsidies? World Development, 91, 11-27.

Chepeliev, M., \& van der Mensbrugghe, D. (2020). Global fossil-fuel subsidy reform and Paris Agreement. Energy Economics, 85, 104598.

Dartanto, T. (2013). Reducing fuel subsidies and the implication on fiscal balance and poverty in Indonesia: a simulation analysis. Energy Policy, 58, 117-134.

Del Granado, F.J.A., Coady, D., \& Gillingham. R. (2012). The unequal benefits of fuel subsidies: a review of evidence for developing countries. World Development, 40(11), 2234-2248.

Davis, L. W. (2017). The environmental cost of global fuel subsidies. The Energy Journal, 38, 7-27.

Ghoddusi, H., Rafizadeh, N., \& Rahmati, M.H. (2018). Price elasticity of gasoline smuggling: A semi-structural estimation approach. Energy Economics, 71, $171-185$.

Ghorbani, A., Rahimpour, M.R., Ghasemi, Y., \& Raeissi, S. (2018). The biodiesel of microalgae as a solution for diesel demand in Iran. Energies, 11(4), 950.

Henseler, M., \& Maisonnave, H. (2018). Low world oil prices: A chance to reform fuel subsidies and promote public transport? A case study for South Africa. Transportation Research Part A, 108, 45-62.

IEA (2020). Tracking Transport 2020. Paris: International Energy Agency.

IPCC (2014). Climate Change 2014: Synthesis Report. Contribution of Working Groups I, II and III to the Fifth Assessment Report of the Intergovernmental Panel on Climate Change [Core Writing Team, R.K. Pachauri and L.A. Meyer (eds.)]. Geneva, Switzerland: IPCC.

Koplow, D., \& Dernbach. J. (2001). Federal fossil fuel subsidies and greenhouse gas emissions: a case study of increasing transparency for fiscal policy. Annual Review of Energy and the Environment, 26, 361-389.

Li, J., \& Sun, C. (2018). Towards a low carbon economy by removing fossil fuel subsidies? China Economic Review, 50, 17-33.

Li, Y., Shi, X., \& Su, B. (2017). Economic, social and environmental impacts of fuel subsidies: A revisit of Malaysia. Energy Policy, 110, 51-61.

Lin, B., \& Lin, A. (2012). Impacts of removing fossil fuel subsidies on China: How large and how to mitigate? Energy, 44, 741-749.

Magné, B., Chateau, J., \& Dellink, R. (2014). Global implications of joint fossil fuel subsidy reform and nuclear phase-out: an economic analysis. Climatic Change, 123(3), 677-690.

Matsuo, T., \& Schmidt, T.S. (2017). Hybridizing low-carbon technology deployment policy and fossil fuel subsidy reform: a climate finance perspective. Environmental Research Letters, 12, 014002.

Merrill, L., Bridle, R., \& Bassi, A. (2015). Tackling Fossil Fuel Subsidies and Climate Change: Levelling the Energy Playing Field. Nordic Council of Ministers.

Ministry of Energy, Science, Technology, Environment and Climate Change (MESTECC), (2018). Malaysia Third National Communication and Second Biennial Update Report to the UNFCCC.

Monasterolo, I., \& Raberto., M. (2019). The impact of phasing out fossil fuel subsidies on the low-carbon transition. Energy Policy, 124, 355-370.

Mundaca, G. (2017). How much can $\mathrm{CO}_{2}$ emissions be reduced if fossil fuel subsidies are removed? Energy Economics, 64, 91-104

Ouyang, X., \& Lin, B. (2014). Impacts of increasing renewable energy subsidies and phasing out fossil fuel subsidies in China. Renewable and Sustainable Energy Reviews, 37, 933-942.

Rashchupkina, Y. (2015). The European Union's role in networks on removal of fossil fuel subsidies and disclosure of climate change information. Contemporary Politics $21(3), 354-366$.

Rentschler, J., \& Bazilian, M. (2017). Reforming fossil fuel subsidies: drivers, barriers and the state of progress. Climate Policy, 17(7), 891-914.

Schwanitz, V.J., Piontek, F., Bertram, C., \& Luderer, G. (2014). Long-term climate policy implications of phasing out fossil fuel subsidies. Energy Policy, 67, 882-894.

Soile, I., \& Mu, X. (2015). Who benefit most from fuel subsidies? Evidence from Nigeria. Energy Policy, 87, 314-324. 
Solarin, S.A. (2020). An environmental impact assessment of fossil fuel subsidies in emerging and developing economies. Environmental Impact Assessment Review, 85,106443

Stefanski, R. (2016). Into the mire: a closer look at fossil fuel subsidies. SPP Research Papers, University of Calgary, 9(10)

Troncoso, K., \& da Silva, A.S. (2017). LPG fuel subsidies in Latin America and the use of solid fuels to cook. Energy Policy, 188-196.

Wesseh, P.K., \& Lin, B. (2017). Options for mitigating the adverse effects of fossil fuel subsidies removal in Ghana. Journal of Cleaner Production, 141, 1445-1453.

Vagliasindi, M. (2013). Implementing Energy Subsidy Reforms: Evidence from Developing Countries. Washington, DC: World Bank. 